\title{
Coronary heart disease, the menopause, and hormone replacement therapy
}

Even in the West of Scotland coronary heart disease (CHD) is uncommon in premenopausal women. ${ }^{1}$ The relation between surgically induced early menopause and an increased risk of cardiovascular disease is undisputed but the increased risk of cardiovascular disease seen with early natural menopause may be explained by its association with cigarette smoking. Does the postmenopausal state increase cardiovascular risk? Data from the United States did not show an increase in "the rate of increase" of death from CHD around or after the menopause. ${ }^{2}$ Likewise a large study in American nurses ${ }^{3}$ did not show any clear increase in cardiovascular mortality and morbidity at the time of the menopause. Poor sensitivity in determining the time of the menopause may make it difficult to establish a relation between the menopause and an increased risk of cardiovascular disease in large population studies such as these.

If premenopausal women are protected by circulating female hormones does hormone replacement therapy (HRT) maintain this protection in postmenopausal women? Much stock is placed on data from the Framingham study ${ }^{4}$ and the influence of the initial results continues. They showed a 1.76 excess relative risk of cardiovascular disease associated with the use of HRT for all cardiovascular outcomes, including angina, but not for total mortality. But this was the only prospective cohort study that showed an adverse effect of oestrogen use on cardiovascular outcome. A later reanalysis that excluded angina and used the harder end points of myocardial infarction, coronary insufficiency, and deaths related to CHD actually showed a beneficial effect on premature death in women aged $50-59$ (relative risk of 0.4 ) with no adverse effect in older women. ${ }^{5}$

The Lipid Research Clinics Program Follow-up Study confirmed the beneficial effect of HRT. ${ }^{6}$ This study followed up 2270 white women aged 40-69 at baseline for an average of 8.5 years and showed an age-adjusted relative risk of cardiovascular disease death of 0.37 for oestrogen users even after account was taken of the potential confounding factors of age, blood pressure, and cigarette smoking. Half of the 32317 women in the American Nurses Health Study, ${ }^{7}$ aged less than 55 had taken HRT: this was associated with a $50 \%$ reduction in the risk of non-fatal and fatal myocardial infarction. ${ }^{7}$ The 10 year follow up from the nurses health study showed that this benefit was maintained but reported that benefit decreased with increasing age. ${ }^{8}$ By contrast Henderson $e t$ $a l^{9}$ in a study of elderly women (median age 75) reported a decrease in mortality with increasing duration of HRT. They found a $40 \%$ reduction in overall mortality in those taking HRT for more than 15 years that was largely due to a reduction in mortality from cardiovascular disease.

There have been more than 20 epidemiological studies of non-contraceptive oestrogen use and CHD risk in postmenopausal women. Over half the studies reported a benefit and most of the remainder showed favourable though non-significant trends; only two showed an adverse trend and this was not statistically significant. Of 16 prospective studies 15 reported beneficial effects, which in most cases were statistically significant. ${ }^{1011}$ Three cross sectional studies have examined the relation between CHD (demonstrated at angiography) and HRT. ${ }^{12-14}$ All three showed significantly less CHD in women who were taking replacement oestrogens, with a risk reduction for severe disease of around $60 \%$ even after adjustment for other CHD risk markers. The greatest benefit on subsequent survival was seen in those in whom CHD had already developed.

These beneficial cardiovascular effects were shown for unopposed oestrogen use. There is justifiable concern about endometrial and breast cancer developing in association with the use of HRT. Endometrial cancer can be prevented by the concomitant use of progesterone, but cyclical bleeding is a major disincentive to taking HRT. The beneficial effects of HRT cannot be fully explained through its actions on plasma lipids. Newer preparations of combined oestrogen and progesterone reduce not only LDL cholesterol but also HDL cholesterol, at least in the short term. ${ }^{15}$ There is concern about the possible adverse effects of progesterone on the lipid profile and until recently the long-term effects of combined oestrogen and progesterone on CHD risk were unclear. It is encouraging that a recent study showed that the combined preparation was also associated with a significantly reduced risk of CHD. So from a cardiological viewpoint it seems reasonable to recommend the combined preparation in postmenopausal women ${ }^{16}$ who have not had a hysterectomy. None the less, the potential gynaecological side effects may make many cardiologists reluctant to initiate therapy. There is obvious scope for close collaboration with gynaecologists.

The question whether the incidence of breast cancer is increased by HRT is unresolved. In an excellent review Speroff considered all the health issues and favoured HRT but he also concluded that the evidence for an increase in incidence and mortality from breast cancer is equivocal. ${ }^{17}$ Any possible excess relative risk is clearly outweighed, at least in mortality terms, by its beneficial effect on CHD. But many women may not be prepared to take HRT while the slightest possibility of an increase in risk of breast cancer remains.

Unbridled enthusiasm for HRT must be tempered by the fact that most studies were observational and thus subject to selection bias. The participants were predominantly white, relatively affluent, and complied with treatment. ${ }^{18}$ Because the health benefits of social class and education are not fully understood it is not possible to adjust fully for them. Compliance with therapy is important and even in patients taking placebo, compliance correlated positively with reduced risk of developing $\mathrm{CHD}$ in intervention trials. ${ }^{19}$ Thus randomised clinical trials are required to determine whether HRT helps to prevent the 
development of CHD in postmenopausal women. Such studies are planned but until the results are known we can only remark that if a therapy that seemed to reduce CHD incidence by $50 \%$ were available to men they would be encouraged to take it.

Royal Alexandra Hospital,

Paisley

IAIN FINDLAY

Royal Brompton and

National Heart Hospital, London

Western Infirmary, Glasgow

DAVID CUNNINGHAM

HENRY J DARGIE

1 Isles CG, Hole DJ, Hawthorne VM, Lever AF. Relation between coronary risk and coronary mortality in women of the Renfrew and Paisley survey: comparison with men. Lancet 1992;339:702-6.

2 Vital statistics of the United States 1983
2 (II) Mortality part B Washington, DC: US Department of Health and Human Services Publication 87-1114, 1987.

3 Colditz GA, Walter BS, Willett WC, et al. Menopause and the risk of coronary heart disease in women. N Engl f Med 1987;316:1 105-10.

4 Wilson PW, Garrison RJ, Castelli WP. Postmenopausal estrogen use, cigarette smoking and cardiovascular disease in women over 50-the Framingham study. $N$ Engl $\mathcal{F}$ Med 1985;313:1038-43.

5 Eaker ED, Castelli WP. Coronary heart disease and its risk factors among women in the Framingham Study. In: Eaker E, Packard B, Wenger NK, Clarkson TB, Tyroler HA, eds. Coronary heart disease in women. New York: Haymarket Doyma 1987:122-32.

6 Bush TL, Barret-Connor E, Cowan LD, et al. Cardiovascular mortality and non-contraceptive estrogen use in women: results from the Lipid
Research Clinics Program Follow-up Study. Circulation 1987;75: 1102-9.

7 Stampfer M, Willett W, Corditz G, Rosner B, Speizer F, Hennekens C. A prospective of postmenopausal estrogen therapy and coronary heart disease. N Engl f Med 1985;313:1044-9.

8 Stampfer MJ, Colditz GA, Willett WC, et al. Postmenopausal estrogen therapy and cardiovascular disease: ten year follow-up from the Nurses therapy and cardiovascular disease: ten year fo
Health Study. $N$ Engl $₹$ Med 1991;325:756-62.

9 Henderson BE, Paganini-Hill A, Ross RK. Decreased mortality in users of estrogen replacement therapy. Arch Intern Med 1991;151:75-8.

10 Barret-Connor E, Bush TL. Estrogen and coronary heart disease in women. $\mathcal{F} A M A 1991 ; 265: 1861-7$.

11 Stampfer MJ, Colditz GA. Estrogen replacement therapy and coronary heart disease: a quantitative assessment of the epidemiologic evidence Prev Med. 1991;20:47-63.

12 Gruchow HW, Anderson AJ, Barboriak JJ, Sobocinski KA. Postmenopausal use of estrogen and occlusion of coronary arteries. Am Heart $\mathcal{7} 1988 ; 115: 954-63$

13 Sullivan J, Vander Zwang R, Lemp GF, et al. Postmenopausal estrogen use and coronary atherosclerosis. Ann Intern Med 1988;108:358-63.

$14 \mathrm{McF}$ arland KF, Boniface ME, Hornung CA, Earnhardt W, Humphries J. Risk factors and noncontraceptive estrogen use in women with and Risk factors and noncontraceptive estrogen use in wom
without coronary disease. Am Heart $\mathcal{f} 1989 ; 117: 1209-14$.

15 Miller VT, La Rossa JC. Sex steroids and lipoproteins. In: Redmond GP, ed. Lipids and women's health. New York: Springer-Verlag, 1990: 48-65.

16 Nabulsi AA, Folsam AR, White A, et al. Association of hormone replacement therapy with various cardiovascular risk factors in postmenopausal women. N Engl f Med 1993;328:1069-75.

17 Speroff $L$. The risk of breast cancer associated with oral contraception and hormone replacement therapy. Women's Health Issues 1992;2: 63-72.

18 Barrett-Connor E. Postmenopausal estrogen and prevention bias. Ann Intern Med 1991;115:455-6.

19 The Coronary Drug Project Research Group. Influence of adherence to treatment and response of cholesterol on mortality in the coronary drug project. $N$ Engl $\mathcal{F}$ Med 1980;303:1038-41.

\section{COMMENTARY}

\section{Arrhythmogenic right ventricular dysplasia: the phenotypic range defined}

In the fully expressed form seen by pathologists the diagnosis of arrhythmogenic right ventricular dysplasia is not difficult. The heart shown here (figure) is typical and it came from a 23 year old man who died suddenly while playing football. There was a history of previous palpitation. The pathology is unmistakable. The right ventricle is dilated

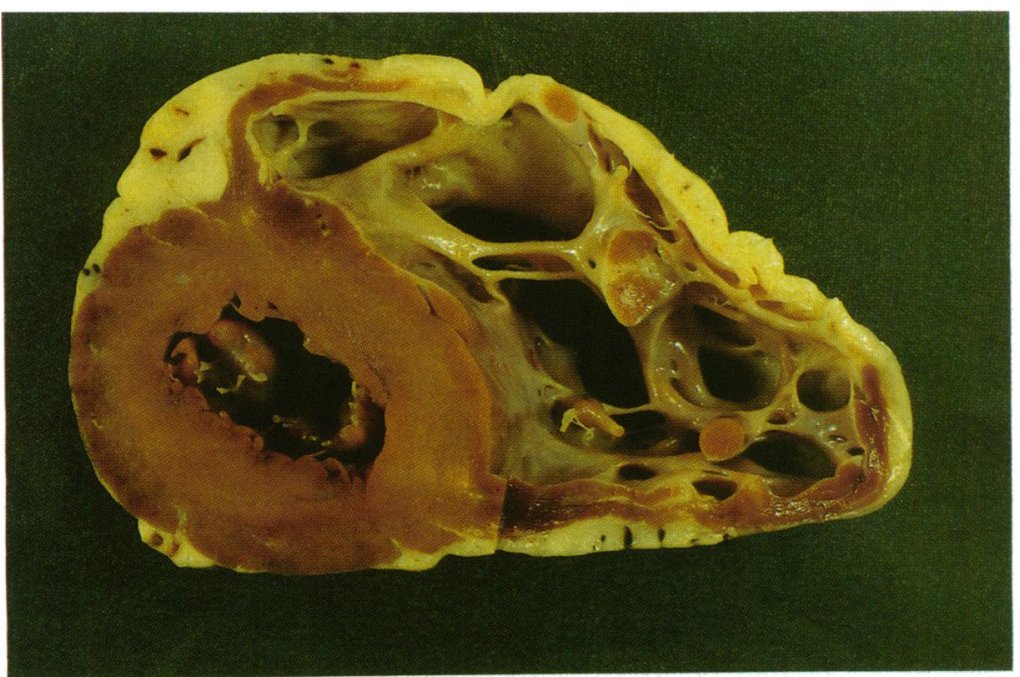

Sudden death on exercise in a man of 23. The right ventricle is dilated and in areas the wall is totally replaced by fat. and there is transmural replacement of the myocardium with fat particularly in the anterior wall. It is a truism that the pathologist sees the worst of every disease but the disease is fully expressed and easily recognised. Studies of large families show a wide clinical expression of arrhythmogenic right ventricular dysplasia in living subjects, many of whom do not have symptoms.

A classic method for defining the gene responsible for any disease is to determine its chromosomal site by linkage with other known chromosomal markers through several generations. For this to be successful, however, it needs to be certain who has the disease and who does not. Laying down a set of criteria for the diagnosis of arrhythmogenic right ventricular dysplasia is a valuable advance. The criteria will also help to establish how common arrhythmogenic right ventiruclar disease is in any particular population. In the United Kingdom the impression among pathologists is that arrhythmogenic right ventricular dysplasia is much less common than hypertrophic cardiomyopathy as a cause of sudden natural death in young adults. The ratio is thought to be lower than 1:10 but may not reflect the true frequency of the disease in living subjects.

MJ DAVIES 